\title{
On the Monetary Causes of Inequality: A Review of the Literature and an Alternate Way Forward
}

\author{
Marco Desogus ${ }^{1}$, Elisa Casu ${ }^{2}$ \\ ${ }^{1}$ Department of Economics and Business Science, University of Cagliari, Cagliari, Italy \\ ${ }^{2}$ Unifidi Sardegna, Cagliari, Italy
}

\section{Email address:}

marcodesogus@gmail.com (M. Desogus), elisacasu@tiscali.it(E. Casu)

\section{To cite this article:}

Marco Desogus, Elisa Casu. On the Monetary Causes of Inequality: A Review of the Literature and an Alternate Way Forward. International Journal of Economics, Finance and Management Sciences. Vol. 8, No. 4, 2020, pp. 156-167. doi: 10.11648/j.ijefm.20200804.14

Received: July 27, 2020; Accepted: August 10, 2020; Published: August 19, 2020

\begin{abstract}
This research re-examines the relations between production, money and income and arrives at a need for reform, through a contemporary money theory, with the same foundations that endow the system of the numerical entity that measures the economy. The analysis undertaken began from the "Econophysics" observation that wealth is unequally distributed among agents in an economic system. The literature has consolidated the concept of 'systemic entropy' as the degree of endogenous 'disorder' that occurs with the succession of interactions/transactions among its elements, leading to a stabilization in equilibrium that is no longer modifiable by spontaneous perturbations, even though there is clear evidence of profound inequality in individual wealth. The contribution offered here is an in-depth investigation into the causes that have led and continue to lead to the genesis and exacerbation of these socio-economic differences, which also convey an exclusion of the less wealthy sectors of the population from the most significant transactions. This ordains the impossibility, at the current state of the art, of achieving a neg-entropic practice, which is fundamental to the evolution of organisms. The point of arrival is in the negation of the monetary structure as currently perceived and organized.
\end{abstract}

Keywords: Econophysics, Quantum Macroeconomics, Monetary Structure, Economic Systems, Inequalities, Production, Money and Income

\section{Introduction}

Pareto noted, first through empirical observations and then analytical evidence, that the probability distribution of income of a population follows a polynomial decay [44].

Given that $a$ is a positive constant, the function of income distribution will be

$$
\left\{\begin{array}{c}
F(w)=0 \text { se } w<a \\
F(w)=1-(a / w)^{p} \text { se } w \geq a
\end{array}\right.
$$

where $w$ is the income of a population ' $\mathrm{P}$ ' distributed with a density $f(w)$; for $w \gg 1$, we will then have

$$
1-F(w)=\int_{w}^{+\infty} f(w) d w \cong w^{-p}
$$

$p$ is Pareto's index ${ }^{1}$ : if $p \leq 1$, the mean value will be

1 Graphically, on a bi-logarithmic scale, $-p$ represents the angular coefficient of the function. infinite. If $p>1$, then the mean value will be finite, and the variance will tend toward infinity. A random non-Gaussian phenomenon is described in this distribution, wherein, compared to a generic positive point of the value $J$, the decay of the probability to not fall within the band $(-J, J)$ is polynomial with $J$ (figure 1).

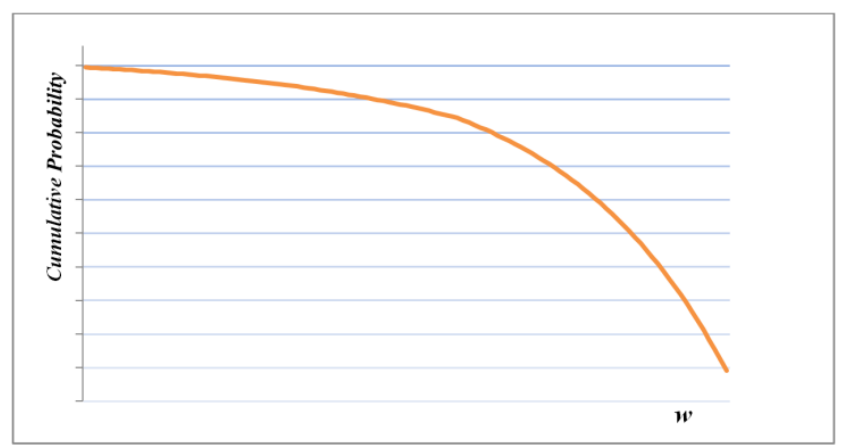

Figure 1. Probability distribution of income of a population. 
In other words, there is a 'power tail' that characterizes the distribution of wealth, which is broken down unequally among the agents pertaining to the population 'P', showing a class (more or less small) with the concentration of great wealth in just a few [5].

In countries with a high internal rate of economic inequality, we can round up the statistically descriptive evidence and go as far as asserting that about $15 \%$ of the population holds half of the total wealth: if it is shown that this band correctly follows the power law referred to in (2), it is then equally true that the same will occur for the poorest share of the remaining population ${ }^{2}$, who - unlike the $15 \%-$ will be assigned a probability of being outside of $(-J, J)$, which decays exponentially with $J$ : this is a Gibbs distribution (figure 2).

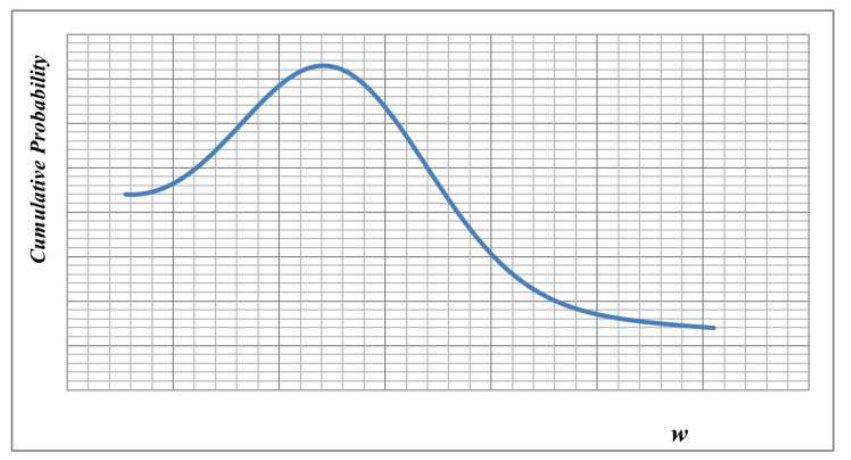

Figure 2. Probability distribution of income for the poorest share of the population.

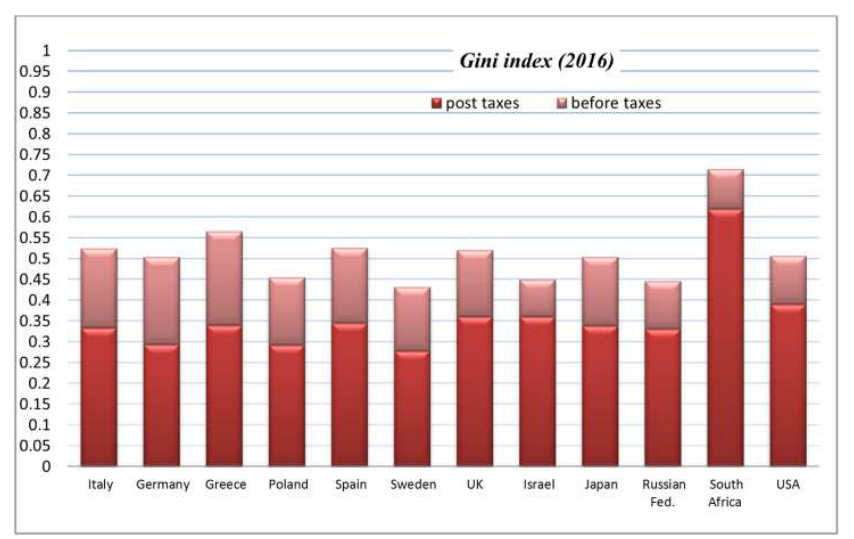

Figure 3. Effect on Gini Index of taxation for wealth redistribution, based on OECD.Stat data.

The comparison of the different statistical behaviour of these two phenomena in figures 1 and 2 icastically illustrates the persistence of the inequalities ${ }^{3}$. Figure 3 also shows that

\section{Approximation based on Oxfam statistics}

3 In a triad of orthogonal Cartesian axes, with $x$ being the vertical axis, and the $y z$ plane being the horizontal section, the rounded surface being $\varphi(x)=\sqrt{y^{2}+z^{2}}$ leads us to determine, at one point $(x, y, z)$, the number of incomes included will be between $x$ and $x+d x$ in the social group related thereto, according to the second product $\sqrt{y^{2}+z^{2}} d x$. This is the surface of the incomes and each relative meridian curve represents the curve of the incomes. Surpassing the considerations of the economist J. B. Say, who spoke of the 'social pyramid' - and observing instead how statistical applications diverge from the pyramid shape - it has been noted that when approaching the horizontal plane the formation of income the redistribution of wealth through proportional forms of taxation only partially attenuates Gini Index levels [24].

To identify the reasons for this persistent state of inequality, it is important to understand how economic interactions between agents and in the present monetary structure determine wealth distribution.

\section{The Distribution of Wealth}

Binary interactions (rectius, transactions) between agents belonging to the system do not constitute an automatic redistribution [60]. Suppose that at every moment of time $t \geq 0$, each agent ${ }^{4}$ has a certain level of wealth $w \geq 0$. Then, imagine that, as a result of exchanges, a part of the wealth of each participating agent is transferred to its own contractor. For example, the wealth $w_{X}$ and $w_{Y}$, belonging to two agents $\mathrm{X}$ and $\mathrm{Y}$ respectively, will change as a result of their interaction in $w_{X}^{*}$ and $w_{Y}^{*}$, according to a linear transaction rule such as

$$
\begin{gathered}
w_{X}^{*}=\frac{1}{2}\left(w_{X}+w_{Y}+\left|w_{X}-w_{Y}\right| v\right) \text { and } w_{Y}^{*}=\frac{1}{2}\left(w_{X}+w_{Y}-\right. \\
\left.\left|w_{X}-w_{Y}\right| v\right)
\end{gathered}
$$

$v$ is an arbitrary unit vector of $\mathbb{R}^{3}$ through the exchange coefficients $^{5} x_{1}, x_{2}, y_{1}, y_{2}$, such that we will have

$$
w_{X}^{*}=x_{1} w_{X}+y_{1} w_{Y} \text { and } w_{Y}^{*}=x_{2} w_{X}+y_{2} w_{Y}
$$

That is to say, there is evidence that the final wealth remains with $\mathrm{X}$ and $\mathrm{Y}$ after each shares their initial wealth, which, as a result of the transaction, was transferred between them.

Now, let's proceed with this line of reasoning by exploring the similarity between the 'kinetic theory of gases' and a generic economic (sub)system to be analysed [61]. The agents belonging to the system are the $N$ particles, which comprise that system ${ }^{6}$, which are intrinsically endowed with a closed and defined volumetric characteristic: like the particles, each agent interacts by virtue of a certain velocity and according to a spatial position vector ${ }^{7}$. In economic terms, these peculiarities can be identified within the interacting agents' initial wealth conditions, their individual protection indexes ${ }^{8}$ and in the random risk components [18, 60].

Making both the mass and frequency of collision equal for

sections more and more approaches a circular shape. The form of income distribution is therefore more correctly identified as a 'social spinning top' (cf. Amoroso, 1925).

4 About which no distinguishing features from the others are known.

5 The rules of the game imply that positive random coefficients should be set, since considering transfers of wealth greater than what is available from either of the actors in the exchange would not be reasonable.

6 Although well aware of the criticism concerning the great difference in the numbers involved in the two systems on which this similarity is being constructed, it is believed that, theoretically, the model can be representative of the evidence of economic inequalities in systems, while opening the way for a rational discussion of their aetiology.

7 Still in the $\mathbb{R}^{3}$ space.

8 That is, each agent's inclination to risk only a part of his/her own wealth (cf. Chakrabarti, 2004). 
all the agents/particles involved and equal to the unit, we can represent the phenomenon according to the law of evolution for the density $f(w, t)$ of the wealth $w$ of each agent over time $t$, through the Boltzmann integro-differential equation modelled on these hypotheses:

$$
\frac{\partial f(w, t)}{\partial t}=Q(f, f)(w, t)=Q_{+}(f, f)(w, t)-f(w, t)
$$

The collision term ' $Q(f, f)(w, t)$ ' shows the variations in density caused by the transactions between the agents. On the whole, equation (5) shows us that, over time $t$, the density changes only due to the effect of internal interactions (binary collisions). The "corrected" term $Q_{+}$also shows the action of transactions on the observable quantities.

Getting back to (4) - then with $w_{X}^{*}$ and $w_{Y}^{*}$ the posttransaction wealth belonging to agents $\mathrm{X}$ and $\mathrm{Y}-\varphi=\varphi(w)$ is the wealth function from which each of the above mentioned observable quantities can be determined. Integrated with respect to $w$, we will obtain the corresponding law of variation over time:

$$
\int_{0}^{+\infty} \varphi(w) Q_{+}(f, f)(w) d w
$$

which, on the mean value of the random quantities $\left\langle\varphi\left(w_{X}^{*}\right)+\right.$ $\left.\varphi\left(w_{Y}^{*}\right)\right\rangle$, is equal to

$$
\frac{1}{2} \iint_{0}^{+\infty}\left\langle\varphi\left(w_{X}^{*}\right)+\varphi\left(w_{Y}^{*}\right)\right\rangle f\left(w_{X}\right) f\left(w_{Y}\right) d w_{X} d w_{Y}
$$
be:

Therefore the variation of the observable quantities will

$$
\begin{gathered}
\frac{d}{d t} \int_{0}^{+\infty} \varphi(w) f(w, t) d w=\int_{0}^{+\infty} \varphi(w)\left[Q_{+}(f, f)-\right. \\
f](w, t) d w
\end{gathered}
$$

And since $f(w)$ is the function of probability density:

$$
\begin{array}{r}
\int_{0}^{+\infty} \varphi(w) f(w) d w=\frac{1}{2} \iint_{0}^{+\infty}\left\langle\varphi\left(w_{X}^{*}\right)+\right. \\
\left.\varphi\left(w_{Y}^{*}\right)\right\rangle f\left(w_{X}\right) f\left(w_{Y}\right) d w_{X} d w_{Y}
\end{array}
$$

From these last two equations we can reflect on the quantities of wealth $\varphi(w)$ not subject to variations following the interaction/transaction

$$
\left\langle\varphi\left(w_{X}^{*}\right)+\varphi\left(w_{Y}^{*}\right)\right\rangle=\varphi\left(w_{X}\right)+\varphi\left(w_{Y}\right)
$$

Which is verified for $\varphi(w)=1$ and for $\varphi(w)=w$. And again, the relation:

$$
\left\langle w_{X}^{*}+w_{Y}^{*}\right\rangle=w_{X}+w_{Y}
$$

is satisfied by a dichotomy of situations:

$$
\left\{\begin{array}{c}
w_{X}^{*}+w_{Y}^{*}=w_{X}+w_{Y} \rightarrow \text { strictly conservative transactions } \\
\text { (one agent wins the other loses) } \\
w_{X}^{*}+w_{Y}^{*} \neq w_{X}+w_{Y} \rightarrow \text { conservative transactions on average } \\
\text { (both agents may either obtain a gain or a loss, however } \\
\text { the total quantity in the system is conserved) }
\end{array}\right.
$$

Much of the literature ${ }^{9}$ focuses on the conservative properties of transactions and on maintaining equilibrium in the system. We observe, however, that conserving this equilibrium also means maintaining the deep inequalities in the system that continue to exclude the less wealthy sections of the population from the most significant transactions [65].

To understand the persistence of this impasse in the distribution of wealth, we begin by examining how evolving theories of value have rendered system normalization at the status quo impossible and arrive at the necessity to reform the production-money-revenue mechanism to rectify the inequal opportunities to access meaningful wealth.

\section{Production, Money and Income}

Dealing with the problem of value in classical economic analysis, and therefore wanting to offer a scientific explanation to observed economic phenomena, Marx raised the problem of the comparison of quantities among different goods and therefore the need to reduce these to one single unit [38].

As is evident in the reasoning of Smith and Ricardo, with general scientific acceptance, 'work' was identified as the value-creating element. Therefore, the problem of how to attribute monetary value to work arose. Marx went so far as to argue that an asset has value because it abstractly represents human work. For classical economists, the role of work assumed a physical dimension, equated with an economic substance comparable to any other commodity. Ricardo also noted that the greater or lesser quantity of work incorporated in goods is the only reason for the variation in their value, which is established definitively once it has been ascertained that all goods are produced by work and that those goods will have no value except through the work done to produce them [45].

The conceptual step that Marx offered seems interesting, as it divides, from a taxonomic standpoint, concrete physical work and abstract work. This then led to the definition of the direct relationship between abstract work and the product. If, however, it is work that is the very foundation of value, its nature cannot be that of value. If through work, products are measured, logically, that same work cannot measure itself. Actually, concrete work and abstract work are two aspects of the same entity, even though the former is understood in its link with physical production and therefore the concretisation of value in use, while the latter represents the creation of exchange value. It was because of this dichotomous aspect, which at the same time differentiates and uniforms the valorisation of products on the market, that Marx also needed to introduce the enlightening definition of abstract work as 'social work'. Therefore, social work is not based on its purely physical dimension, such as land or capital, but has the capacity to transform the - economically inert - object produced into goods, which as an entity, has exchange value. Abstract work, viewed as a social attribution, then allows the 
generation of a specific economic form-value for the outputs, which evolve from the purely instrumental - belonging to the work once it has exited the production processes. The social attribute refers to the quality of the work's ability to incorporate specific relations and its own production relationships within a given economic system. This aspect actually reduces the arbitrary nature of the attribution of the exchange value to the point of cancelling it, while conferring a precise causal link between socially necessary work and the product it generates. [8]

In essence, if Smith is trying to demonstrate that the value of goods is in some way functional to the amount of work contained in those goods and has as his analytical objective determining the value of work, then Marx is supporting the dual nature of work, where real work is nothing more than a productive factor: it will be abstract work that determines the expression of economic measure. The vulnerability of this reasoning lies, however, in the logical principle that - on any subject - clearly, the measured and the measurer cannot belong to the same essence. In an economic environment, work and goods are different categories and, markedly, it is not correct to proceed with the estimation of the latter through something that in turn must be measured. Although Marx rejected the idea that work should be considered as something that could be valorised much like a commodity, he in one way conceived it as a dimensional standard by any means [15] - nevertheless, he circuitously measured work in work time [38]. Hence, in an attempt to grasp the value of goods starting from human work, the theoretical objective focused on converting the different heterogeneous jobs into point units on a uniform time basis - so-called 'simple work' - such as a universal minimum common measurement key. This however inevitably leads to the use - in the final instance - of a dimensional parameter and it clearly contradicts the aforementioned necessary independence of the measurer from what will later be measured.

It is exactly this paradox that opened the way to neoclassical economic theory, which is driven by an attempt to overcome such a construct.

The unit of measure must be a numerical entity, or one borrowed from arithmetic: this aspect is fully and unreservedly acceptable. The way that has been sought to measure value is monetary. And there is no opposition to the idea that work (paid) is still at the origin of value because it immediately produces exchange value, i.e. money. Or rather, not work in and of itself - since it is incompatible in its position as the principle creator of value [15] - but through, precisely, money, which gives the numerical form-value of measurement.

The shift to the neoclassical idea of the value of goods, mainly through Walras' ideas, leads to a theoretical system completely free from the dimensional presupposition. Starting from value in use, not meant as a basis for production and the establishment of exchange parameters, but as a basis for the definition of price relativity, an exasperated image is generated, where it is not even important to define the entity of the processed product, since, in fact, it is not (yet) considered a value.

In this conceptual context, measurement would only be of goods involved in an exchange situation, since it is from trade, and in the resulting equivalences established in the market, that numerical prices can be generated. Moreover, this pricing starts arbitrarily from an absolute attribution of value in one of the goods, itself subject to comparison [25]. What follows is not limited to the conception of an exchange relationship between two goods - whose existence is not at all disputed - but to theoretically forcing the determination of that relationship through the meeting/clashing of the antagonistic pressures among the functions of supply and demand. This inevitably leads to a defining impasse, where the relative prices appear to emerge from the point of contact between the two forces mentioned above. Each force, however, evokes its own influence toward the maximization point, a result whose fundamental terms of departure - which should have determined the same exchange - are neither known nor inferable; value assignation is rather specious [6].

Some intuitions closer to the direction of these thematic arguments can be found in Keynes' discourse, specifically in his development of the concept of wage units as a factor for the measurement of work. The English economist presents valuable ideas for the definition of the issue. He definitively surpasses the idea of work as a commodity, observing it instead - solely - as the principle creator of goods. In this scientific arrangement, therefore, one can see that wages are not the price of work $^{10}$ : if they were, one would deny the classical axiom, which contradicts any concept of work's nature as merchandise. However, to a certain degree, the wage units of a certain economic product are counted through the payment of those wages: when work is assigned a dimensionless numerical expression - money - it is instantly associated with the product. The product, having acquired a monetary form, becomes an economic object, which is measured in a standardized manner. The operation of paying wages integrates the product into the money. Therefore, wage units are the units used to measure the product. Money, understood as a simple numerical form, is associated with products through the payment of wages and products become their real content. The salary units proposed by Keynes are precisely the units of account available to the economy [15]. Keynes went on, however, to maintain that human work was physically heterogeneous and, hence, that a unit of time doing a certain job would be measured differently from other jobs. This once again returns us to the long-standing question of the "measurement of the unit of measure". Yet, at the same time, it leads us to ascertain that the only way to understand the ecology of the phenomenon is through the attribution of a numerical (monetary) form, which, with the payment of wages, is immediately integrated into the product.

10 Income is not a price (cf. Schmitt, 1972, 1975 and Cencini, 2001, 2008), it is the product itself as the content of a numerical (monetary) form. 


\section{For a Reorganization of the Monetary Structure}

To address this dilemma around the determination of value, let us look at the contribution of 'theory of money emissions' [55]. This is an abstract framework, based on a renewed conception of money, which emphasizes its rotatory nature, and which allows the "movement" of real goods. What is introduced into the social system comprehensively comprises these goods and not the medium in which they are permitted to move.

To grasp the essence of bank money as an instrument of circulation, it is necessary to consider money itself in its momentary existence and not as a reserve of wealth, as it is summarily perceived while it is inactive, between payments [55]. This understanding, crucially, allows us to reconsider how wealth is defined and dispersed among various economic agents.

Money enters the real world and is used according to the logical rules governing the modern business of banking. It has a vehicular nature; its endogenous character provides the objective numerical measurement of economic transactions. In an instantaneous cycle, it returns to its starting point at the very moment it is issued, given that each payment involves the creation-destruction of the intangible excipient necessary for the circulation of goods among economic agents. This consideration relates the purchasing power of money to the process of production. Being the result of the monetization of the total costs of production, monetary income is the very embodiment of real production. Therefore, the conceptual object that acts as a means of payment is distinguished from that which represents a temporary seat of purchasing power [43]. This clarification is not merely semantic, since it introduces a fundamental ontological distinction that improves our understanding of bank money, even though it is in contrast with the common idea that the term 'money' and the term 'deposit' are synonymous. Bank deposits do not cease to exist in the period between one payment and the next, although within that period it is better to talk about a bank balance rather than money. Money and payments are the same thing and there is no money before or after a given payment [56]. Indeed, while bank deposits have a duration in time, it only takes a microsecond (i.e. a duration in time approximating zero ${ }^{11}$ ) for a payment to be entered into a bank account system [48].

Banks are the only institutions with the right to issue legally accepted payment instruments, using the accounting principle known as "double-entry bookkeeping" [46]. To comprehend the foundations of bank money, it is in fact fundamental to highlight the nature of its accounting [36]. While the double-entry account consists of recording payments, the visible accounts only show the resulting balances (both positive and negative), which are merely the

11 Newton explained that the last ratio of two evanescent quantities was to be understood as the ratio of the quantities not before they vanish, nor after they have vanished, but with which they vanish. results of the payments and not the actual money. Doubleentry accounting therefore records the result of monetary flows and not those same flows [46]. Nevertheless, this heterodox conceptual shift should not be identified with a set of neoclassical conditions of equilibrium. The simultaneity of the monetary manifestation with payments is in fact a fundamental law of bank money, which is true, regardless of the idiosyncratic characteristics of the agents' behaviour [12].

The 'quantum conception of production' suggests a particular representation of time, capable of overcoming the conventional conception of "perceivable" or historic time, or rather, that continuous flow in which production activities take place. This is done by introducing the idea of a 'quantum of time', which is an interval, which emerges as an indivisible "unit" within continuous time, which defines a product in economic terms.

The product is the end result of the process that takes place in continuous time $\left[t_{0}, t_{n}\right]$ but that arises as an economic event only in $t_{n}$. In an emission that is both corpuscular and undulatory, the instantaneous existence of production in $t_{n}$ includes the entire period $\left[t_{0} \rightarrow t_{n}\right]$ : "on a quantum of time, production does not take place in time but it actually is time" [55]. At any moment of the continuous time preceding the completion of the product, the production itself remains null in absolute terms.

However, production is a physical process in motion, which presupposes the existence of an intellectual project whose final realization will retroactively define a quantity of matter and energy in the productive sphere through the absorption of the realization that occurs in the corresponding interval [55]. Unlike what can be observed in continuous time $\left[t_{0}, t_{n}\right][4]$, production can be defined positively in any quantum interval of the same continuum. The demonstration of this would then require a conception of time that simultaneously captures the instant in which production becomes a positive action - full realization of the project - and the corresponding quantum, that is, the space-time process in its totality. Cencini argues that quanta of time are a logical necessity in economic theory [10]. Production is redefined by transforming a continuum of time into a quantum. Each production defines a quantum: a real and instantaneous emission, which "quantifies" time [55].

In essence, according to quantum macroeconomic analysis, physical production, and therefore the amount of time needed to physically produce a product, is emitted at the moment when economic production occurs. This philosophical idea of time summarizes two fundamental principles of quantum economy: wages are the unit of measurement of the economy and production (and its opposite, consumption) is an instantaneous event ${ }^{12}$.

In this context, money is added as a numerical form that provides uniformity of the reference value for all goods and

12 This conception fits well into the framework of the monetary theory of production held by Keynes (1933/1973), since production can be considered as the primary economic operation, which necessarily precedes any exchange (cf. Schmitt, 1975). 
services produced [47]. Money then acquires a positive value and thus a positive purchasing power over economic production [14] through its conceptual association with production itself ${ }^{13}$. In the money supply theory, money only represents an incorporeal standard, which provides the economy with numbers and which allows the holistic measurement and circulation of economic production [54]. Production is intrinsically devoid of any homogeneous valuesubstance [10].

It is necessary to transcend the view that money, as such, expresses a positive value - representative of purchasing power - issued by the banking system to allow the settlement of internal transactions among economic agents. This conception would give the banking system the option of creatio ex nihilo of units of purchasing power [62]. At that point, the domestic payment system would operate by endowing the economic system with a net patrimony without, however, the constraint of the related production.

It seems superfluous to point out that the basic rule of double-entry accounting imposes the logical equivalence of both sections of the balance sheet. In the literature we can often see the attempt to consider gold as the real equivalent of the money issued in the country. If this methodology were followed in any event and without too much approximation, one can deduce that at this time in history, the total domestic production has replaced the precious metal in the assets of the country's bank balance sheet, so that domestic money is created against the gross domestic product (GDP). Similar ideas can nevertheless be drawn from an imperfect analysis of bank money, affected by the lack of distinction between the form and the object of the payments.

It is therefore necessary to advance in the analysis with a necessary connection to Smith's famous concept of the "great wheel of circulation". The great wheel of circulation is completely different from the goods that circulate in it. The results of the system are completely comprised in these goods and not in the wheel that allows them to move. If money were merely the counterpart of the domestic product, it would be sufficient to measure 'money mass' and GDP to gain a quantitative measure of the country's total wealth. However, this would also be equivalent to identifying monetary instruments with net assets, also used as an intermediate good to facilitate exchange in terms of real products among the economic agents.

Therefore, despite first impressions and perceptions, advanced monetary science would never confirm such conclusions. Indeed, a thorough examination of (monetary) payments would inevitably demonstrate that money and real goods form a single essence, one amount whose peculiarity is precisely that of understanding the two nominal and real features [55]. Consequently, money is not an intermediary of trade, as indicated in the neo-Walrasian monetary models of general equilibrium [17, 59]. It is instead nothing more than the vehicle that moves goods among economic

13 If we borrow de Saussure's linguistic perspective (1916), goods and services are "signifier" objects, while money is the final "signification." operators. Money is the numerical form in which the units of purchasing power are expressed, and this - as has been said before - was probably understood by both Marx and Keynes.

Each (monetary) payment is at the same time an exchange.

Also peculiar - and it cannot help but be - is the role of the banking system in providing the numerical medium for the circulation of production. Indeed, every time a payment is made, a circular flow of money can be found. In their role as monetary intermediaries, banks limit themselves to providing the economy with a numerical instrument that they recall immediately [12]. The issue of money is at the same time the creation and the destruction of the algebraic means necessary to measure and circulate goods. On a practical level, this statement is supported by the mechanics of double-entry accounting, which guarantee the instantaneous matching of the numbers entered in the asset column with those in the liability column of any balance sheet.

Every payment has two aspects, one that is numerical and one that is real, and involves three poles: the payer, the beneficiary and the banking system. Inside of any binary exchange between two generic agents $\mathrm{X}$ and $\mathrm{Y}-$ in one single gesture - money is issued, the borrower (agent $\mathrm{Y}$ ) becomes a debtor of the bank and the agent $(\mathrm{X})$ who receives payment becomes a creditor of the same bank. The object of agent X's right towards the bank or, in general, towards the banking system as a whole, is precisely the purchasing power that the same bank lends to $\mathrm{Y}[29,46]$. From a different standpoint, when an operator sells a real good (A), he essentially exchanges it for a financial right (good B), which provides him with an equivalent right to draw on domestic production. It can be said that bank deposits represent the good par excellence, as they have as their object the total domestic product - with which they are identified - before final consumption. At the same time, they define the monetary form capable of assigning it a numerical expression [37].

If money were introduced into the economic system through the exchange process, it would be too late to give it objective purchasing power over current production.

With a few notable exceptions, the most widespread literature on monetary economics shows common consensus on the fact that money has the capacity to circulate among the public thanks to its acceptance, by convention, on the market. This orientation is also deeply rooted in science: "if everyone, including the public sector and foreigners, was prepared to accept the liability of any intermediary, whether it be bank, building society, or insurance company, as final settlement for any debt, then the deposits of that intermediary would become equivalent to legal tender for all practical purposes" [28]. However, the precariousness of a system based on a similar social contract between functional groups of operators, having different, if not already antithetical, economic interests, seems evident [46]. The question of the issue of money is, however, less complicated than this presumed process of continuous collective bargaining. Indeed, it is an integral 
and inborn part of the economy and has not been selected among a range of alternatives [22].

Let us look at the factor market, where the relationship between money and the new physical production arises, whose effective result is the formation of domestic income.

Neoclassical models do not explain the origins of the agents' initial endowments, and the conjecture remains that production is a particular case of exchange, that is, the replacement of a production service for a product. This has two dramatic consequences: (1) money might not be an objective measure of economic production; (2) there will never be any macroeconomic income. In this scenario, workers (W) sell their productive services to enterprises (E). Then the workers buy the result of the production process from the enterprises (newly produced goods). Overall production is perceived as the sum of all exchanges occurring transversally between two different markets: that is the productive factor market and the product market, in which every purchase in the former or in the latter market determines for the same operator a contextual and equivalent sale in the latter or in the former, respectively. It follows that the exchange - in the production process - cannot be measured in monetary terms because the money, in a scheme so represented, necessarily plays the role of cash goods, closing the reasoning in the faulty correspondence of the same as 'intermediate goods' [46].

This places before us two considerations, which, by dichotomous logic, evidently exclude one another: (a) if money is actually a good, even though in essence it is sui generis, then it cannot weight real production since money itself must be measured; (b) vice versa, if money does not belong to a group of products, then it cannot be its own counterpart in any example of exchange, whether in the product market or in the production factor market.

By analogy, general equilibrium models cannot explain the existence of one of the main macroeconomic quantities of capitalist systems: domestic income. Since neoclassical economic theory continues to argue that income is generated by the difference between sales and purchases in the product market, the genesis of a net revenue for the overall economic system cannot be justified. The theory of general equilibrium illustrates how, in the product market, household purchases (i.e. $S$ workers) determine the profit of enterprises $(E)$, which is invested circularly in the production factor market to acquire productive services. On the whole, the income spent (-) by $S$ for the purchase of newly manufactured goods is earned $(+)$ by enterprises $E$, thus outlining a zero-sum game with which the domestic (net) income can never be explained reasonably [46].

"On a more sophisticated level, the logical flaw of received monetary theory can be best highlighted by referring to the conception of absolute exchange worked out by B. Schmitt over the last forty years. Starting from both the numerical and vehicular nature of (bank) money and endorsing Keynes's still unorthodox analysis on wage-units, it is indeed possible to provide a rigorous and logical explanation of the production-consumption process occurring in contemporary national economies" [46]. In domestic economies, income is defined as the exchange between two simultaneous issues: one monetary and one real [15]. This exchange, like all other types of payment ${ }^{14}$, is made by the same agent $(S)$, thus justifying the expression 'absolute exchange', conceived by Schmitt, who used it for the first time in 1966 [52]. This is the same as saying that in a monetary production economy there is only one category of agents, that is, the set of families, because, as Schumpeter has already argued, companies are simple intermediaries between the workers and the same enterprises [57].

Production is a complex action that results in monetary income, which in turn takes form and is generated between two flows relating to the same economic agent. In contrast to mainstream economic theories, workers pay themselves, since they transform the real flow represented by the composite and physically heterogeneous result of their work into its identical and uniform expression of cash flow in the form of bank deposits through the banking system's instrumental issue. Therefore, monetary income has real purchasing power due to the very fact that it is homologous with the gross domestic product [3]. The absolute exchange that occurs in the sphere of production is therefore a macroeconomic operation, since monetary income defines a positive and concrete dimension for the domestic economy as a whole.

"Money-income denotes the national output, and is therefore a real commodity, while a sum of money, taken as such, is a purely numerical and immaterial form" [56]: through the absolute exchange that takes place in the production factor market, newly manufactured goods, which are evidently physically dissimilar and multiple, acquire a homogeneous and coherent numerical form that allows them to be measured for economic purposes. Hence, this brings us to the acknowledgement that the only operation that allows money and production to be integrated is obviously the payment of wages and the homologous conception of a 'goods-salary'.

In short, therefore, given that the payment of wages defines the collective income or, in the same manner, the total cost of current production, it seems correct to affirm that work is the only production factor. Nevertheless, this does not necessarily mean that households acquire all new production goods if they spend their monetary income on the product market. Neither would it be marginal nor contradictory, though one might instead consider it meaningful, to affirm that the creation of domestic income is equivalent to the sum of wages received, as well as to the extent that the expenditure of income contributes to the generation, at least partial, of its redistribution. This is extremely plausible, since the first statement mainly concerns the production factor market, while the next statement concerns the product market, where the establishment of retail prices changes the distribution of income and contributes to the generation of profit [3].

14 That is to say, those that occur in product markets or financial markets. 


\section{Macroeconomic Pathologies and Inflationary Profits}

With this theoretical context, we now focus our analysis on the causes of economic inequality. With an economic structure that operates on incorrect assumptions of work, production and value, it is inevitable that certain macroeconomic pathologies arise in the absence of a wellregulated system of payments.

This, as profits invested - and the related payment of workers who produce the capital goods (which "fill" the money) - give rise, on the one hand, to the acquisition of fixed capital by the company and, at the same time, to the entitlement of the workers to a right to withdraw from the stock created. The process of formation of fixed capital is functional to the investment of profit. However, the current disorder in our domestic accounting, outlined in the previous section, does not allow this operation to be implemented and recorded in accordance with the conceptual differentiation between money, income and capital.

An income already invested (profit is an income) and therefore transformed into fixed capital should not yet be available on the financial market [23]. The persistence of this incorrect process causes an accumulation of capital that is not consistent with production, causing those pathologies such as (first) inflation and, in the longer term, deflationary conjunctures and consequent unemployment.

Furthermore, consumption is the effect of income expenditure on the product market. Workers (households) are the (initial) owners of all newly produced goods and services at the same time that wages are paid. According to the monetary theory accepted here, it is necessary for the two types of consumption to be distinguished analytically. First, expenditure in the product market is a form of income destruction, since physical goods are released from the monetary form in which they were represented pro tempore by income holders. It is also necessary to reiterate that, second, the payment of wages is ipso facto a creation. However, this is true (only) in the case that investment of profit becomes an expense - in the production factor market - whose object is actual production.

From a macroeconomic standpoint, an absolute exchange that takes place in the quantum production process defines the economic consumption of newly manufactured goods, since the material result of the work is converted, through the intermediation of the banking system, into an exactly equivalent deposit receipt $[55,46]$. Therefore, newly manufactured goods clearly lose their physical dimension when converted into monetary income, whose purchasing power coincides with those very same products. From this point of view, the specificity of the production-consumption process is easy to see. Income generated is immediately recorded as a right of withdrawal (bank deposit) from the domestic product.

Turning the analysis toward the product market, where income holders obtain the physical object represented by their bank deposit, one can note that the expenditure of income used to purchase goods allows workers to take possession of the value in use produced by the same workers (assuming, for reasons of explanation, that profits equal zero).

Let us now consider both the contemporaneous payment of wages and their final expenditure in the market for the goods produced. The first item concerns the input market and represents the formation of domestic income. The second entry derives from the result of the income expenditure for the purchase of current production and requires the monetary intermediation of the banking system [46]. The final purchase of current production by households can be summarised as another variant of an absolute exchange, where workers replace their monetary income with real goods. The monetary form in which the units of purchasing power were contained dissolves, releasing its material meaning, i.e. the domestic product. Therefore, the creation of income and its destruction are two absolute exchanges with opposite signs. The former, which we will call an absolute positive exchange, defines the transformation of current production into monetary income, while the latter, which is the absolute negative exchange, defines the transformation of income into physical production [11].

It is then clear that imbalanced capital accumulation and derivative ills of inflation and unemployment are caused, in large part, by the present disordered accounting system. Nevertheless, such macroeconomic ills are not due to the behaviour of the agents, as neoclassical economists argue, but to monetary and institutional anomalies that affect the accumulation process itself.

Without taking the economic impact of innovation, technological changes, knowledge and spillover effects into account here, but starting from the analysis of the current, incorrect, dynamics of the use of profits as mentioned above, we see that profits are duplicated in the process of income formation, thus generating a deposit that never runs out [55] and allowing capital to be constantly - and detrimentally taken up.

To understand this toll better, we look at the issue of 'inflationary profits'. These are made when global supply is not sufficient to satisfy demand; "[windfall] profits must be regarded, not as part of the earnings of the community [...], but as increasing (or, if negative as diminishing) the value of the accumulated wealth of the entrepreneurs" [33].

If, as we have seen, normal profits are produced from the income generated by the production of the goods-wages, inflationary profits are typical of the nominal increase of monetary units. As healthy profit, its investment and correct amortization $^{15}$ represent proper macroeconomic dynamics. The process of over-accumulation arising from a defective monetary structure, however, creates pathologies in the economic system. Additional investment of inflationary profit leads, in fact, to the issue of money, which at this point, is empty and lacks real content. Therefore, it has become $a$ non-

15 Macroeconomic amortisation is the goods production process aimed at restoring the loss of value in fixed capital due to natural obsolescence and wear. 
income, which evidently determines an additional demand of an inflationary type. Amortization of fixed capital of pathological origins leads to a continuous increase of the same capital, whose remuneration requires increasing interest, the limit of which, based on the logical rationales discussed, comes to the total amount of wages. As soon as the interest reaches this threshold, it is no longer appropriate for the remuneration of the capital. This profit, being constantly excessive, cannot be invested in the capital goods market and will find its place in the consumer goods or the financial markets [20]. This last phase determines the greater part of bank loan business, supported by the preponderance of these forms of capital in the system, with a consequent increase in the level of indebtedness of the less well-off agents and further accentuation of inequality [32]. This additional "wealth", commensurate with an empty monetary liquidity system, is easily transmitted to company managers and capitalists, multiplying the recourse to financial investments [31], thus emphasizing the trends described in the introduction.

Moreover, the replacement of productive investments with speculative loans increasingly reduces the economy's real content, raises unemployment levels and exposes the economic system to crisis.

\section{Exclusive Transactions and the Persistence of Inequalities}

Given the persistence of the foregoing disorders, let us look at what happens, rebus sic stantibus, inside economic systems. Let us proceed, therefore, by introducing the Arrhenius ${ }^{16}$ equation, suitably adapted to the systemic dynamics of interaction among economic agents:

$$
k w=k w_{0} e^{-\frac{\Delta W^{\dagger}}{M L}}
$$

Where:

1. $k w$ is the wealth constant (endowment)

2. $k w_{0}$ is the pre-exponential factor, which is also the constant for moderate fluctuations in the system's liquidity levels

3. $\Delta W^{\dagger}$ is the "activation wealth": again, borrowed from chemical kinetics. Like activation energy, it is the minimum quantity of wealth required to trigger the binary collisions or transactions among agents. Indeed, repulsive forces can be observed around each potential interaction, made up of entry barriers for significant exchanges and by the levels of individual protection, which are inversely proportional - in percentage - to the income levels of each actor. Only if the wealth available is sufficient to override the repulsive field will it be possible to activate the transaction and organize the exchange.

4. $M$ represents the random variable of the macroeconomic context and indicates the scenario in which the agents interact. This takes into account the

16 Swedish chemist and physicist awarded the Nobel prize for chemistry in 1903 .
GDP, the system account balance, the total (monetary) liquidity, the number $(N)$ of the agents involved, as well as - residually - any qualitative components and intangible assets.

5. $L$ is liquidity.

Therefore, the rationalization is that the wealth constant may depend on the inverse liquidity exponent, deducing a dependence based on the Boltzmann distribution.

Focusing our attention on the collisions or transactions, based on what Arrhenius found for chemical reactions, mutatis mutandis, assuming that the steric factor and the number of interactions are (almost) insensitive to liquidity:

$$
\frac{d k w}{d L}-\frac{\Delta W^{\dagger}}{M L^{2}} k w=0
$$

From which

$$
\frac{d k w}{k w}=\frac{\Delta W^{\dagger}}{M L^{2}} d L
$$

and, by integrating both members according to a Dirichlet condition

$$
\int_{k w_{0}}^{k w} \frac{1}{k w} d k w=\int_{L_{0}}^{L} \frac{\Delta W^{\dagger}}{M L^{2}} d L
$$

solving

$$
\ln k w-\ln k w_{0}=-\frac{\Delta W^{\dagger}}{M L}
$$

which takes us back to (12)

$$
k w=k w_{0} e^{-\frac{\Delta W^{\dagger}}{M L}}
$$

Graphically, expressing $\ln k w$ as a function of $\frac{1}{L}$, we obtain a line that intercepts at the $\ln k w_{0}$ origin and the angular coefficient $-\frac{\Delta W^{\dagger}}{M}$. This representation allows us to establish which, among certain competitive interactions or transactions, will be the most favoured. By virtue of the attitude of the lines thus constructed, the equation that describes the winner, at a certain level of liquidity, will be the one with the corresponding value in the lower ordinate. The eventual point of intersection of the two lines establishes the level of equivalence or indifference and indicates the beginning of the interval of liquidity levels in which the reversal of the advantage can be seen (figure 4).

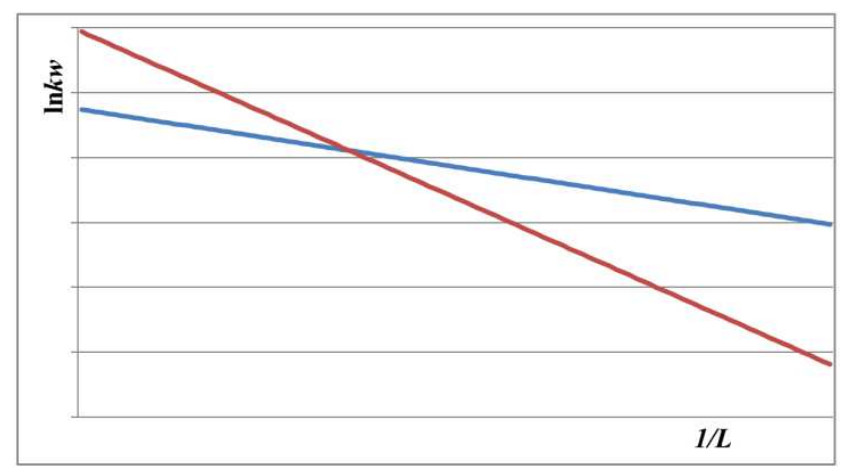

Figure 4. Conditions of transactions between competing economic agents. 
The case of the absence of points of intersection of the lines (figure 5) is interesting for the purposes of this paper. This situation is where one transaction has an absolute advantage over another, which is the transaction that demands the lesser activation wealth (the lower line in the diagram) and that generates lowest or negligible exchange values.

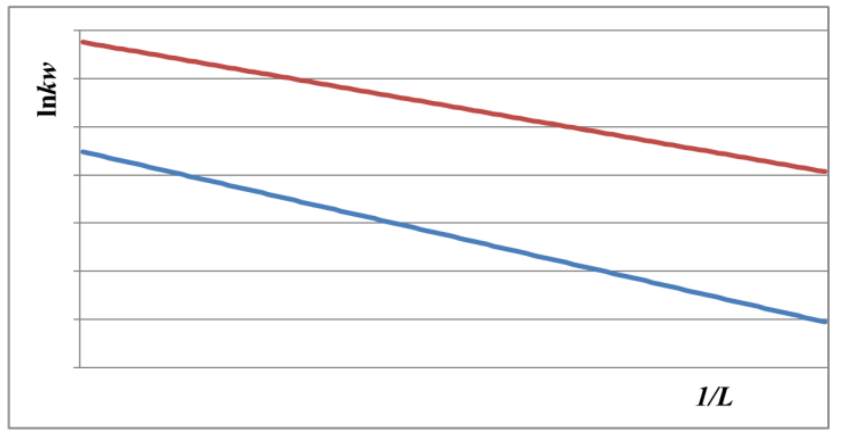

Figure 5. Conditions of transactions when an agent has absolute advantage.

\section{Example of the casino}

The system is a casino, comprising 100 gaming tables. 90 tables accept medium to low bets with a limited maximum chance of winning and a limited stock in the bank. The remaining 10 have high entry minimums and equally high winnings available. The wagers of the former represent the lowest line in the chart, where a higher frequency of participation and low exclusion can be seen. However, it is on the tenth of the richest tables where there are the most significant transactions, but which can only be accessed by the smallest share of agents favoured by the strongest activation wealth.

What is clear is that the majority of agents, with little activation wealth, are excluded from the richest exchanges. This explains both the preservation of the system in balance (Pareto efficiency), and the persistence of inequalities.

\section{From Entropy to Economic logos}

To address and mend the inequalities inherent to current economic systems, we find that a reorganization of monetary structures to reflect quantum conceptualizations of production and income creation and is commensurate with domestic accounts is in order.

The theoretical threads earlier followed in our paper demonstrate how various classical and neo-classical models of production, work and value resulted in faulty accounting systems. Widely accepted, double-entry bookkeeping enabled an over-accumulation of empty capital that introduced such macroeconomic pathologies as inflation and unemployment. Unproductive in nature, this excess capital then diverts wealth to financial markets in the form of loans payable to the dominant wealthy few.

As Marx noted, the index of entropy represents an "internal dissipation of social energy". This expresses the point at which spontaneous interactions among agents produce effects confined within the limits of the preservation of the acquired stability (Pareto equilibrium). However, the Pareto efficiency promoted by the present economic system engenders inequality; indeed, as the distribution of wealth continues to skew, the activation wealth becomes increasingly difficult for all but the wealthiest to achieve. Markets continue to invite access to the most significant transactions, and therefore a significant portion of total wealth and overall socio-economic benefit, to a select few.

Order, economic logos and the restoration of greater equality and inclusion in markets require conscious action at a level of correct regulation of fundamental structures that support the socio-economic system. As we suggest, this begins by recalibrating fundamental understandings of the nature of production, money and income as well as the relationships between them in line with quantum macroeconomic theory. Accounting methods, too, require reworking to prevent the inflationary profits that lead to overaccumulations of capital and wealth by lenders in the top tier.

\section{For COI Statement}

Compliance with Ethical Standards.

\section{Funding}

The authors declare that their research has been entirely self-funded.

\section{Conflict of Interest}

The authors declare that they have no conflict of interest.

\section{References}

[1] Amoroso, L. (1925). Ricerche intorno alla curva dei redditi. Annali di Matematica Pura e Applicata, Serie IV Tomo XXI, 123-159.

[2] Arrhenius, S. (1915). Quantitative laws in biological chemistry. London: G. Bell and sons.

[3] Bailly, J. (2017). Rethinking exchange and prices. In Rochon L. P. and Rossi S. (eds), A Modern Guide to Rethinking Economics, pp. 90-113. Cheltenham: Edward Elgar Publishing.

[4] Bergson, H. (1946). The Creative Mind: An Introduction to Metaphysics. New York: Kensington Publishing Corp.

[5] Berman, Y., Ben-Jacob, E. and Shapira, Y. (2016). The Dynamics of Wealth Inequality and the Effect of Income Distribution. PLOS ONE, Vol. 11, no. 4.

[6] Bloch, H. (2020). Price Theory, Historically Considered: Smith, Ricardo, Marshall and Beyond. History of Economics Review, Vol. 75, no. 1, 50-73.

[7] Boltzmann, L. (1872/1995). Weitere Studien über das Wärmegleichgewicht unter Gasmolekülen. Sitzungsberichte der keiserlichen Akademie der Wissenschaften, 66, 275-370. Translation: Brush, S. G. (2003), Further studies on the thermal equilibrium of gas molecules. In Kinetic Theory of Gases: An Anthology of Classic Papers With Historical Comment, pp. 362-368. London: Imperial College Press. 
[8] Bradley, X. (2017). Inflation and Unemployment. In Bailly J., Cencini A., and Rossi S. (eds.), Quantum Macroeconomics, pp. 50-63. Oxon and New York: Routledge.

[9] Cencini, A. (1984). Time and the Macroeconomic Analysis of Income, London and New York: Pinter.

[10] Cencini, A. (1985). L'analyse de la production et production circulaire, échange et théorie quantique. In Schmitt B. (ed), Production et Monnaie, Cahier de la Revue d'économie politique. Paris: Sirey.

[11] Cencini, A. (1988). Money, Income and Time, with a Preface by Meghnad Desai. London and New York: Pinter Publishers.

[12] Cencini, A. (1995/1997). Monetary Theory. National and International. London and New York: Routledge.

[13] Cencini, A. (2001). Monetary Macroeconomics. A New Approach. London and New York: Routledge.

[14] Cencini, A. (2005). Macroeconomic Foundations of Macroeconomics. London and New York: Routledge.

[15] Cencini, A. (2008). Elementi di Macroeconomia monetaria. Padova: Cedam.

[16] Chatterjee, A., Chakrabarti, B. K. and Manna, S. S. (2004). Pareto law in a kinetic model of market with random saving propensity. Physica A, Vol. 335, 155-163.

[17] Clower, R. W. (1969). Monetary Theory: Selected Readings. Harmondsworth: Penguin.

[18] Cordier, S., Pareschi, L. and Toscani, G. (2005). On a kinetic model for a simple market economy. Journal of Statistical Physics, Vol. 120, 253-277.

[19] D'addario, R. (1949). Ricerche sulla curva dei redditi. Giornale degli Economisti e Annali di Economia Nuova Serie, Anno 8, 1/2, 91-114.

[20] de Medeiros C.A. and Amico F. (2019). Financialization and Capital Accumulation, Journal of Economic Issues, Vol. 53, no. 2, 587-594.

[21] de Saussure, F. (1916). Cours de linguistique générale, Losanna-Parigi: Payot.

[22] Deleplace, G. and Nell, E. J. (1996), Money in Motion: The Post Keynesian and Circulation Approaches, London and Basingstoke: Macmillan.

[23] Desogus, M. and Casu, E. (2018). Essays in innovative risk management methods based on deterministic, stochastic and quantum approaches. Quanah, TX: Anaphora Literary Press.

[24] Duncan, D., Sabirianova Peter, K. (2016). Unequal inequalities: Do progressive taxes reduce income inequality?. International Tax and Public Finance, Vol. 23, 762-783.

[25] Fântână, R. S. (2016). The exchange activity and quantic economics. Revista Economica, vol. 68, no. 2.

[26] Gibbs, W. (1914). Elementary principles in statistical mechanics, developed with special reference to the rational foundations of thermodynamics. New Haven: Yale University Press.

[27] Gini, C. (1921). Measurement of Inequality and Incomes, The Economic Journal, Vol. 31, 124-126.
[28] Goodhart, C. A. E. (1989). Money, Information and Uncertainty. London: Macmillan International Higher Education.

[29] Graziani, A. (1989). The Theory of the Monetary Circuit. Thames Papers in Political Economy, Spring, 1-26.

[30] Harck, S. (2017). Real-wage versus wage-share targets in an open-economy model of the wage and price dynamics, Review of Keynesian Economics, Vol. 5, no. 2, 276-299.

[31] Hoffmann, A. and Schnabl, G. (2016). Adverse Effects of Ultra-Loose Monetary Policies on Investment, Growth and Income Distribution. CESifo Working Paper Series, no. 5754.

[32] Ivanova, M. N. (2020). Marx's Theory of Money: A Reappraisal in the Light of Unconventional Monetary Policy. Review of Radical Political Economics, Vol. 52, no. 1, 137 151.

[33] Keynes, J. M. (1930/1971). A Treatise on Money: Vol. 1 - The Pure Theory of Money; Vol. 2 - The Applied Theory of Money. London: Macmillan.

[34] Keynes, J. M. (1933/1973). A Monetary Theory of Production. London: Macmillan.

[35] Keynes, J. M. (1936/1973). The General Theory of Employment, Interest and Money, London: Macmillan.

[36] Keynes, J. M. (1937). Alternative Theories of the Rate of Interest. Economic Journal 47, 241-252.

[37] Lawson, T. (2018). The Constitution and Nature of Money. Cambridge Journal of Economics, Vol. 42, no. 3, 851-873.

[38] Marx, K. (1857/1973). Grundrisse: Foundations of the Critique of Political Economy. London: Penguin.

[39] Marx, K. (1867/1976). Capital: A Critique of Political Economy, Vol. 1, London: Penguin.

[40] Marx, K. (1885/1986). Capital: A Critique of Political Economy, Vol. 2, Moscow: Progress Publishers.

[41] Marx, K. (1894/1984). Capital: A Critique of Political Economy, Vol. 3, London: Lawrence \& Wishart.

[42] Matthes, D. and Toscani, G. (2008). On steady distributions of kinetic models of conservative economies. Journal of Statistical Physics Vol. 130, 1087-1117.

[43] Orrell, D. (2016) 'A Quantum Theory of Money and Value.' Economic Thought, Vol. 5, no. 2, 19-28.

[44] Pareto, V. (1897). Cours d'èconomie politique, Lausanne and Paris: Rouge.

[45] Ricardo, D. (1817/1951). On the Principles of Political Economy and Taxation. Cambridge: Cambridge University Press.

[46] Rossi, S. (1998). Endogenous Money and Banking Activity: Some Notes on the Workings of Modern Payment Systems. Studi Economici 53, 23-56.

[47] Rossi, S. (2001). Money and Inflation: A New Macroeconomic Analysis. Cheltenham: Edward Elgar.

[48] Rossi, S. (2006). The theory of money emissions. In Arestis P., Sawyer M. (eds.), A Handbook of Alternative Monetary Economics. Cheltenham and Northampton: Edward Elgar. 
[49] Rossi, S. (2007). Money and Payments in Theory and Practice. London and New York: Routledge.

[50] Say, J. B. (1852). Cours complet d'économie politique pratique. Paris: Guillaumin.

[51] Schmitt, B. (1960). La formation Du Pouvoir D'Achat. Paris: Sirey.

[52] Schmitt, B. (1966). Monnaie, Salaires et Profits. Presses Universitaires de France, Albeuve: Castella.

[53] Schmitt, B. (1972). Macroeconomic Theory. A Fundamental Revision, Albeuve: Castella.

[54] Schmitt, B. (1975), Théorie Unitaire de la Monnaie, Nationale et International, Albeuve: Castella.

[55] Schmitt, B. (1984). Inflation, Chômage et Malformations du Capital, Paris and Albeuve: Economica Et Castella.

[56] Schmitt, B. (1996). A New Paradigm for the Determination of Money Prices. In Deleplace, G. and Nell, E. J. (eds), Money in Motion, pp. 84-118. London and Basingstoke: Macmillan And St. Martin's Press.

[57] Schumpeter, J. A. (1954/1994). History of Economic Analysis. London and New York: Routledge.

[58] Smith, A. (1776/1976). An Inquiry into the Nature and Causes of the Wealth of Nations. New York: Oxford University Press.
[59] Starr, R. M. (1989). General Equilibrium Models of Monetary Economies: Studies in the Static Foundations of Monetary Theory (Economic Theory, Econometrics, and Mathematical Economics). Boston: Academic Press (Harcourt Brace Jovanovich).

[60] Thébault, K., Bradley, S. and Reutlinger, A. (2018). Modelling Inequality. The British Journal for the Philosophy of Science, Vol. 69, no. 3, 691-718.

[61] Toscani, G. (2016). Sulle code di potenza di Pareto. Matematica, Cultura e Società. Rivista dell'Unione Matematica Italiana - Serie 1, Vol. 1, 21-30.

[62] Villani, C. (2003). Cercignani's conjecture is sometimes true and always almost true. Commun. Math. Phys. 234, 455-490.

[63] Vivian, R., \& Spearman, N. (2016). Banks and Money Creation 'Out of Nothing', Working Paper, December 2016. EU and Comparative Law Issues and Challenges Series.

[64] Walras, L. (1952). Eléments d'économie politique pure, ou la théorie de la richessesociale. Paris: Librairiegenerale De Droit Et De Jurisprudence.

[65] Yakovenko, V. M. (2016). Monetary economics from econophysics perspective. European Physical Journal Special Topics, Vol. 225, 3313-3335. 